\title{
IUGS at a crossroads
}

With the theme of the 31st International Geological Congress in Rio de Janeiro (Geology and Sustainable Development: Challenges for the Third Millennium) in mind, I start my term as the new IUGS President in a team of dedicated and highly qualified officers, with the ambition to steer IUGS into new directions. Huge and still increasing societal needs generated from an unwise use of the earth demand immediate application of the knowledge that we as geoscientists may offer. It is crystal clear that society could save lots of lives and money if our professional capabilities were properly applied in decision-making in the political arena. Therefore it should be our first priority to communicate our knowledge to those who, often unconsciously, suffer from the lack of such knowledge. Nevertheless, many of our fellow geoscientists are not yet sufficiently aware of their possibilities and potentials in making active contributions to solving or mitigating societal problems. Increasing awareness among our colleagues is the second message that IUGS proclaims.

With reference to my first point, IUGS should put our planet Earth more prominently on the political agenda, but IUGS cannot do this alone. We need the support of other non-governmental organisations and United Nations. In the next four years our team will work hard towards an International Year of the Earth. In conjunction with this ambition, IUGS, with its sister organisations in the International Council of Sciences, will develop new initiatives for joint projects on applied or fun- damental sciences. For example, IUGS will support initiatives in the field of biogeology in general and of medical geology in particular. Beyond the life sciences there are ample possibilities to embark on joint operations with social and economic sciences, such as providing geological input to decision making and management processes. New developments in information technology already make broadening of our fields feasible today.

If society would demand more input from the geosciences indeed, politicians would be prepared to support more fundamental geological studies too. In several countries we now witness an explosive growth of $\mathrm{PhD}$ studies on a better understanding of the earth in general and on earth processes in particular. For IUGS, therefore, both the fundamental and the applied studies are important. However, so far IUGS has been merely strongly identified with the fundamental sciences. Although extremely important for a better understanding of our planet, continuation on that track only would in the end be lethal for our profession. Therefore, IUGS is at a crossroads now. Building on the good work done by the outgoing team, the new IUGS Executive Committee aims to find new roads towards a better future for our profession and to build robust bridges with related and unrelated disciplines.

\section{Ed F.J. de Mulder IUGS President}

